\title{
Enkripsi Base 64, Hashing SHA1 dan MD5 pada QR Code Presensi Kuliah \\ ${ }^{1}$ Harry Witriyono, ${ }^{2}$ Sandhy Fernandez \\ 1,2Universitas Muhammadiyah Bengkulu, Indonesia \\ 1harrywitriyono@gmail.com; ${ }^{2}$ sandhy fernandez@gmail.com;
}

\begin{tabular}{l}
\hline Article Info \\
\hline Article history: \\
Received, xxx xx xxxx \\
Revised, xxx xx xxxx \\
Accepted, xxx xx xxx \\
\hline Kata Kunci: \\
quick response code \\
base 64 \\
sha1 \\
md5 \\
presence \\
\hline \hline
\end{tabular}

\begin{abstract}
ABSTRAK
Aplikasi presensi perkuliahan di Universitas Muhammadiyah Bengkulu perlu sekali dikembangkan sehingga lebih mudah dalam proses pelaksanaannya. Salah satu cara untuk mempermudah prosesnya menggunakan presensi Quick Response Code yang dapat dilakukan dalam kondisi perkuliahan daring ataupun luring. Metode yang digunakan adalah berupa penyimpanan Uniform Resource Locator terenkripsi dan ter-hashing yang dikombinasikan dengan filterisasi internet protocol address sehingga informasi yang tersimpan pada Quick Response Code menjadi lebih aman dibandingkan bila dalam bentuk teks biasa. Metode pengumpulan data dengan menggunakan teknik observasi dan wawancara terhadap pengguna aplikasi terdahulu baru kemudian dilakukan analisa, perancangan dan pemrograman secara eksperimen pada modul-modul program yang berperan dalam proses presensi tersebut. Dari hasil penelitian ini Quick Response Code dapat terproteksi dan berhasil digunakan serta dapat berintegrasi dengan beberapa learning management system, aplikasi media sosial yang digunakan oleh dosen khususnya di Universitas Muhammadiyah Bengkulu. Hasil penelitian ini telah digunakan pada proses perkuliahan di Semester Genap Tahun Akademik 2020 ini.
\end{abstract}

\section{ABSTRACT}

Keywords:

quick response code base 64

shal

$m d 5$

presence

The lecture attendance application at the University of Muhammadiyah Bengkulu needs to be developed so that it is easier in the implementation process. One way to simplify the process is to use the presence of a Quick Response Code which can be done in online or offline lectures. The method used is in the form of encrypted and hashed Uniform Resource Locator storage combined with internet protocol address filtering so that the information stored in the Quick Response Code becomes more secure than in plain text. The data collection method uses observation and interview techniques to previous application users and then analysis, design and experimental programming are carried out on program modules that play a role in the presence process. From the results of this study, the Quick Response Code can be protected and used successfully and can be integrated with several learning management systems, social media applications that are often used by lecturers, especially at the University of Muhammadiyah Bengkulu. The results of this study have been used in the lecture process in the Even Semester of the 2020 Academic Year.

This is an open access article under the CC BY-SAlicense.

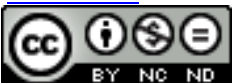

\section{Penulis Korespondensi:}

Harry Witriyono,

Program Studi Teknik Informatika,

Universitas Muhammadiyah Bengkulu,

Email: harrywitriyono@gmail.com

\section{PENDAHULUAN}

Salah satu indikator motivasi keberhasilan proses akademik yang terjadi di Universitas Muhammadiyah Bengkulu adalah pencatatan kehadiran dosen dan mahasiswa pada kegiatan perkuliahan yang berlangsung atau yang dikenal dengan istilah absensi / presensi kehadiran. Permasalahan selama ini adalah dosen memanggil satu per satu mahasiswa dan harus hadir bersama mahasiswanya sehingga menyita sebagian waktu pembelajaran. Hal ini sejalan dengan pernyataan 
dari beberapa hasil penelitian [1] dan [2] serta [3] bahwa proses presensi menjadikan acuan kedisiplinan dan tolok ukur kinerja serta motivasi pegawai. Selain itu pada presensi di kuliah daring beberapa faktor kecurangan yang dilakukan mahasiswa pada proses presensi sering terjadi.

Untuk mengatasi masalah itu perlu dicari cara sehingga proses presensi tidak terlalu menyita waktu dan dapat dilaksanakan baik dalam bentuk perkuliahan daring di learning management systems (LMS) ataupun perkuliahan luring di kelas. Salah satu metode yang ditawarkan adalah menggunakan Quick Response (QR) code yang terhubung ke bagian program sistem presensi yang dapat mencegah terjadinya kecurangan pada prosesnya [4]. Selain itu kode QR dapat memberikan kepraktisan ditampilkan di halaman LMS atau di layar proyektor di kelas.

Permasalahan lainnya adalah perlunya pengamanan informasi Uniform Resource Locator (URL) yang tersimpan di kode QR yang akan digunakan pada sistem informasi akademik pengelola presensi kuliah, sehingga tidak mudah terbaca dan aman dari proses Structured Query Language Injection dan ancaman keamanan siber lainnya. Untuk menjaga keamanan suatu sistem informasi sehingga keaslian informasinya terjaga digunakan secured hash algorithm [5].

Tidak cukup dengan algoritma hash, pengamanan sistem juga dapat dengan algoritma enkripsi dan dekripsi base 64. Base 64 dapat digunakan untuk pencegahan SQL injection pada URL suatu sistem informasi [6]. Pemilihan algoritma tersebut agar informasi yang dienkripsi dapat kembali menjadi teks sebelumnya.

Pengamanan informasi yang lain adalah berupa kombinasi dari algoritma hashing Secured Hashing Algorithm 1 (SHA1) dengan Message Digest Algorithm 5 (MD5) seperti yang telah dibuktikan pada hasil penelitian sistem penjadwalan karyawan [7]. Dengan demikian diharapkan keamanan informasi menjadi lebih aman dari kombinasi beberapa metode dan algoritma yang ada.

Selain itu untuk internet protocol address (IP) juga dapat digunakan untuk mendeteksi dari mana sumber data berasal pada suatu jaringan. Penggunaan IP filtering dapat digunakan untuk mengkontrol mana yang diijinkan dan tidak diijinkan masuk ke dalam suatu jaringan [8]. Dengan demikian diharapkan filterisasi IP dari pengguna dapat mencegah kecurangan penggunaan perangkat ketika melakukan presensi secara daring.

Berdasarkan permasalahan dan beberapa hasil penelitian tadi, maka pada penelitian ini akan menggabungkan kombinasi pengamanan 2 algoritma hashing SHA1 dan MD5 dengan enkripsi base 64 serta ip filtering sehingga diharapkan informasi URL yang tersimpan di kode QR untuk memproses presensi perkuliahan menjadi aman dan sekaligus memberikan kemudahan dalam prosesnya serta terjaganya otentikasi asal datanya.

\section{METODE PENELITIAN}

Penelitian dimulai dengan mengumpulkan informasi yang informasi yang dibutuhkan dengan cara wawancara kepada stakeholder aplikasi sistem akademik khususnya pada proses presensi perkuliahan hingga terbentuknya informasi bagi kepentingan pelaporan akademik. Selain itu wawancara juga dilakukan pada pengguna sistem sebelum penerapan modul yang diteliti.

Selain wawancara untuk pengumpulan data dari pengguna, digunakan juga cara observasi dan studi pustaka sehingga didapatkan informasi tambahan bagi pelaksanaan penelitian. Observasi meliputi analisa struktur basisdata sistem lama dan relasi antar tabel-tabel yang dibutuhkan untuk proses presensi perkuliahan.

Setelah semua informasi yang dibutuhkan tersedia maka dilakukan metode eksperimental untuk pembuatan desain antar muka pengguna yang baru dan pembuatan modul program presensi baru yang mendukung penggunaan teknologi kode QR dengan menerapkan metode enkripsi base 64, hashing SHA1 dan MD5 serta memfilter IP address yang digunakan mahasiswa untuk proses presensi nantinya.

Struktur tabel yang digunakan untuk penyimpanan item presensi dari setiap dosen yang mengampu mata kuliah tersimpan pada tabel Presensi yang tampak pada Gambar 1. Tabel Presensi digunakan untuk menyimpan setiap item pertemuan dari jadwal perkuliahan yang diampu oleh dosen. 
JSAI : Journal Scientific and Applied Informatics

Vol. 4, No. 2, Juni 2021, hal. 263 272

E-ISSN: 2614-3054; P-ISSN: 2614-3062, accredited by Kemenristekdikti, Sinta 5

DOI: 10.36085

Tabel ini mempunyai kunci primer PresensiID dan kunci tamu DosenID yang menjadi kunci utama pembeda kode $\mathrm{QR}$ untuk presensi.

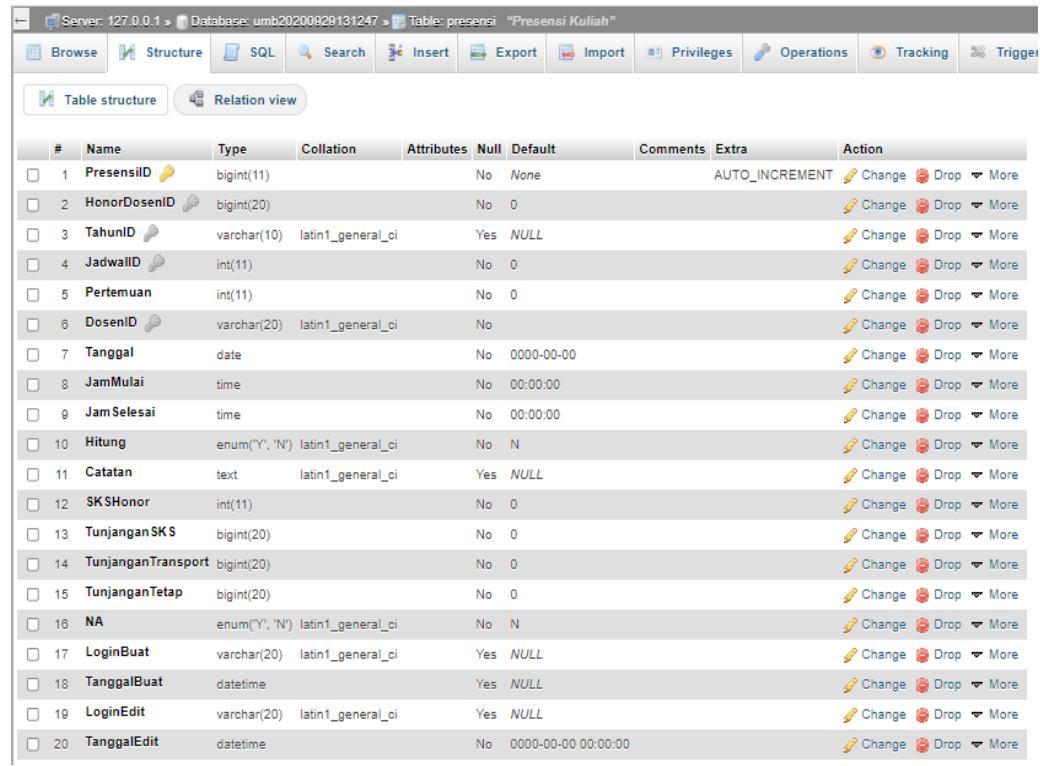

Gambar 1. Struktur Tabel Presensi

Secara garis besar alur program pembentukan kode QR untuk presensinya adalah seperti tampak pada Gambar 2. Kode PresensiID yang terbentuk ketika Dosen membuat item pertemuan pada jadwal kuliah terbentuk secara otomatis dengan memanfaatkan fungsi auto increment dari struktur tabel basis data. DosenID didapat dari saat dosen login ketika membuat item pertemuan pada jadwal kuliah yang diampunya. Setelah kedua kunci primer itu tersimpan di tabel presensi maka keduanya dilakukan proses hashing SHA1, dan kemudian dilakukan proses enkripsi Base 64, disusun sebagai parameter URI dan kemudian di hashing MD5 dan akhirnya dijadikan data unik pada setiap kode QR untuk proses presensi.

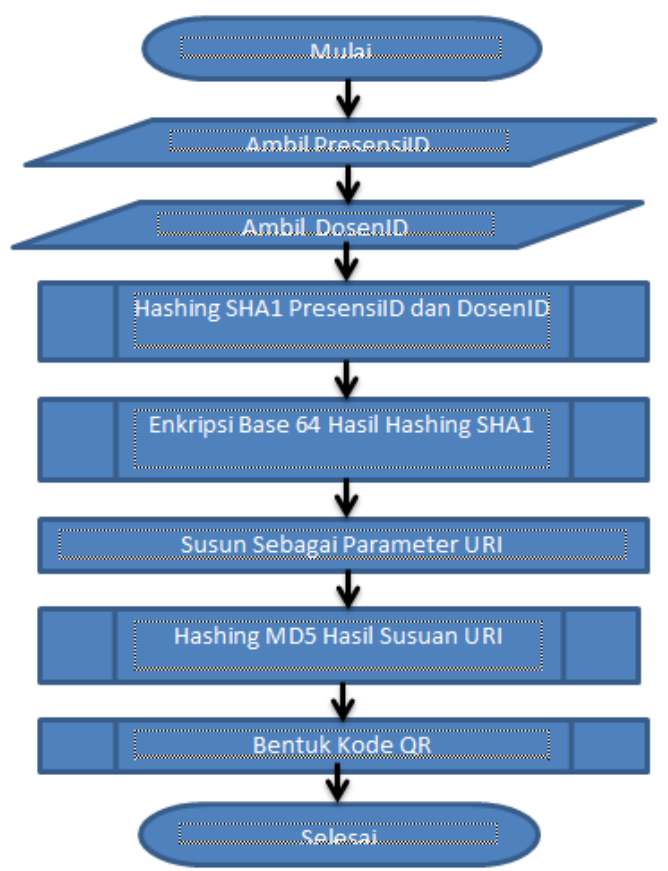

Gambar 2. Diagram Flowchart Pembentukan Kode QR

Selanjutnya untuk mencatat presensi dari mahasiswa tabel yang digunakan adalah tabel Presensimhsw yang tampak pada Gambar 3. Tabel ini mempunyai kunci tamu PresensiID yang menghubungkannya ke tabel Presensi. Pada tabel ini ditambahkan kolom kodeunik yang digunakan 
untuk menyimpan nilai hashing SHA1 dari IP address ketika melakukan presensi dan menjadi identifikasi pengamanan agar mahasiswa lain tidak menggunakan perangkat yang sama saat melakukan presensi pada satu item jadwal perkuliahan yang diikuti bersama teman-temannya.

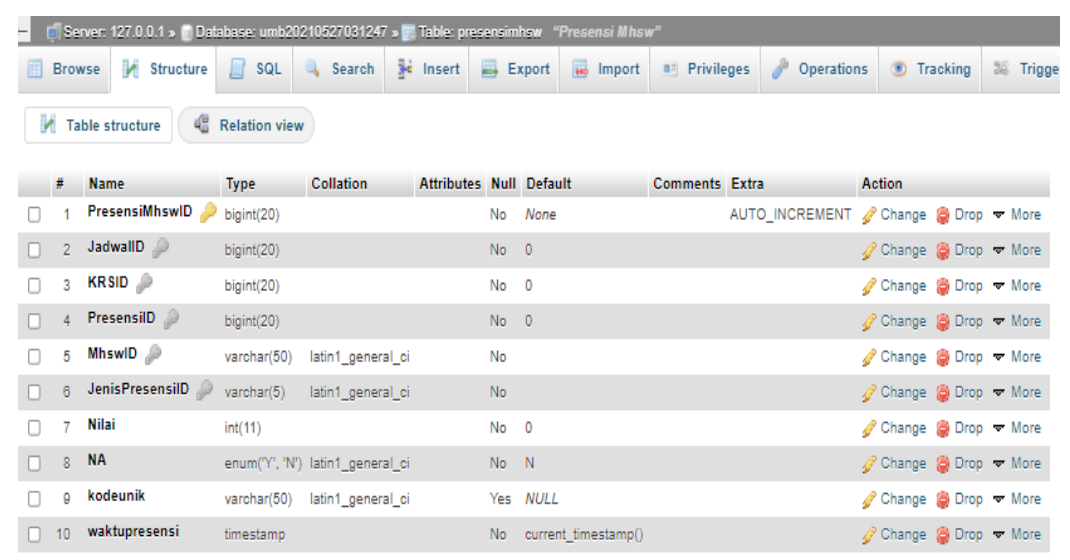

Gambar 3. Struktur Tabel Presensimhsw.

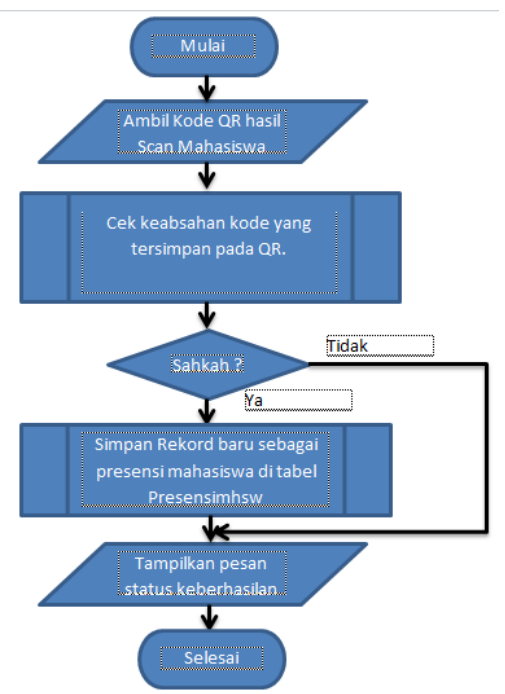

Gambar 4. Diagram Flowchart Pemrosesan Kode QR Presensi

Gambar 4 menjelaskan diagram alir pemrosesan kode QR yang dikirimkan setelah mahasiswa melakukan proses pindai dari kode QR yang didapatnya dari dosen. Kode QR yang berisi Uniform Resource Indentifier yang telah terenkripsi dan ter-hashing tersebut selanjutnya diperiksa keabsahannya sesuai tidaknya dengan yang dikirimkan oleh dosen dan mahasiswa yang melakukan presensi. Bila ternyata tidak sah, maka proses presensi gagal dan tidak tercatat pada tabel presensimhsw, sebaliknya bila sah maka proses presensi baru dicatatkan sebagai rekord pada tabel presensimhsw.

Data pengujian pada penelitian adalah data yang telah tersimpan di server basisdata Sistem Akademik Universitas Muhammadiyah Bengkulu. Data utama pengujian adalah data Semester Genap Tahun Akademik 2020/2021 hingga masa tengah semester. Jumlah mahasiswa sampel yang digunakan sebanyak 143 orang dari 2 dosen pengampu pada 5 mata kuliah berbeda yang diampu.

\section{HASIL DAN ANALISIS}

Kode QR adalah gambaran dua dimensi yang dikembangkan anak prusahaan dari Toyota, Denso Wave di Jepang pada tahun 1994 [9]. Penerapannya dalam bahasa pemrograman PHP menggunakan kode pustaka QR yang tersedia di http://phpqrcode.sourceforge.net, yang dikembangkan dari C libqrencode library (ver. 3.1.1), Copyright (C) 2006-2010 pada Kentaro Fukuchi bersifat open source (LGPL) dan berguna menghasilkan kode QR. 
Penggunaan PHP QRcode library tersebut dikarenakan sistem yang lama dibangun dalam bahasa pemrograman php. Hal ini memang sangat tepat penggunaannya bagi aplikasi yang dijalankan pada server dan digunakan pada jaringan luas [10] dan [11]. Dengan dasar itulah maka peneliti tetap mempertahankan bahasa pemrograman yang digunakan untuk pembuatan modul pembentuk kode QR dan pemroses dari kode QR yang dipindai oleh mahasiswa dalam proses presensi perkuliahannya.

Kode QR hasil penelitian ini menyimpan Uniform Resource Locator (URL) dari program pemroses kode QR untuk presensi. Hal ini sejalan dengan pendapat Ashford dari George Fox University pada artikel hasil risetnya bahwa biasanya pada kode QR dapat disimpan URL, pesan pendek, tulisan atau nomor telepon dengan berbagai variasi ukuran [12]. Tampilan isi dari kode QR hasil penelitian ini tampak pada Gambar 5 yang merupakan hasil dari pembacaan aplikasi pemindai QR yang banyak tersedia di Google Play Store atau di Apple Store. Pada gambar tersebut tampak bahwa program pembaca proses presensi tersimpan di URL http://siakad.umb.ac.id dengan bagianbagian Uniform Resource Identifier (URI) yang terenkripsi dan ter-hashing. Selanjutnya mahasiswa melakukan pemanggilan dengan menekan tombol Open Link.

\section{SCANNED RESULT}

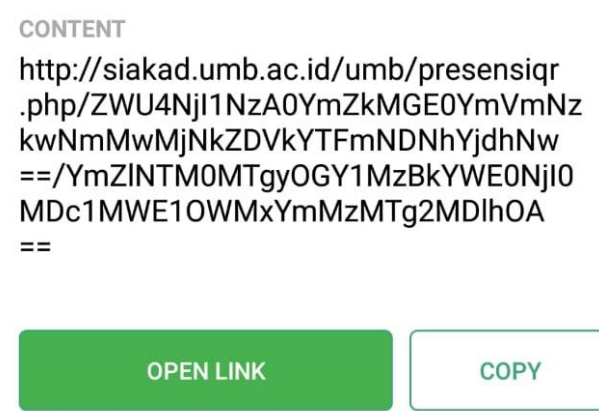

Gambar 5. Tampilan Kode QR pada Salah Satu Aplikasi Pemindai Kode QR.

Pada penelitian ini pemrosesan validasi hasil pindai kode QR dengan metode Representational State Transfer (REST). Pemilihan metode ini karena merupakan metode yang ideal untuk berbagai interaksi pada aplikasi web secara keseluruhan [13]. Parameter yang dikirimkan pada metode REST di penelitian ini tampak pada URI ke 4 dan ke 5 seperti yang tampak pada Gambar 5. URI tersebut selanjutnya akan digunakan sebagai bagian penting identifikasi pembeda item perkuliahan dan dosen pengampu perkuliahan yang dihadiri oleh mahasiswa yang melakukan pemindaian kode QR tersebut.

Pengacakan kode URI ke 4 dan ke 5 pada kode yang tersimpan di kode QR hasil penelitian ini merupakan kombinasi antara metode enkripsi Base 64 dan hashing SHA1 serta hashing MD5. Pemilihan metode ini sejalan dengan penelitian bahwa kombinasi hashing dan salt akan meningkatkan keamanan suatu password [14]. Walaupun demikian berbeda dengan penelitian terdahulu, bahwa pada penelitian ini proses salt- nya menggunakan enkripsi Base 64 dan hashing MD5. Gambar 6 menunjukkan potongan kode php pada program pembentuk kode QR yang menerapkan proses enkripsi dan hashing tadi. 


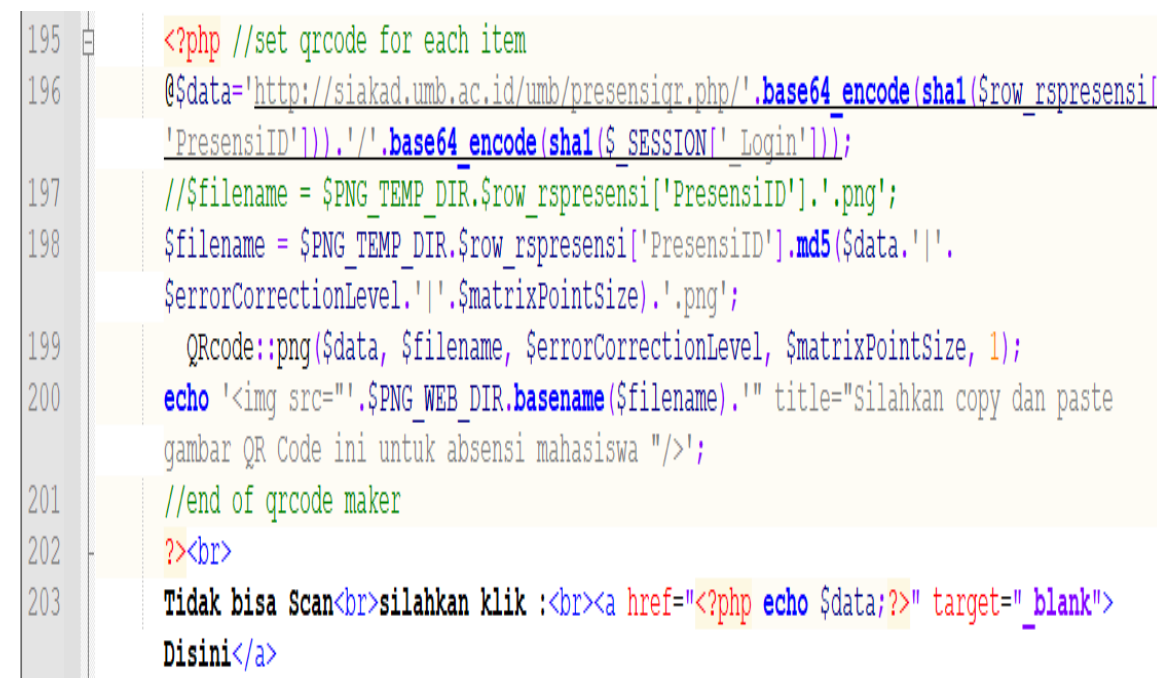

Gambar 6. Kode Program PHP Pembentuk Kode QR yang Terenkripsi dan Ter-hashing.

Penerapan kode QR dan metode-metode enkripsi dan hashing ternyata membutuhkan pengubahan struktur tabel presensimhsw pada sistem lama sehingga ditambahkan kolom Kodeunik yang akan menyimpan hashing SHA1 dari ip publik mahasiswa yang melakukan presensi dan sekaligus menjadi bagian kunci pendeteksi agar tidak terjadi presensi ganda dan kecurangan yang dilakukan mahasiswa dengan melakukan presensi temannya pada perangkat yang sama. Selain itu ditambahkan kolom Waktupresensi yang juga menjadi kunci agar tidak terjadi kecurangan dan sekaligus sebagai kolom yang dapat digunakan sebagai audit bagi informasi saat pelaksanaan presensi oleh mahasiswa. Perubahan struktur tersebut terlihat pada Gambar 3.

Penambahan kolom Kodeunik yang menyimpan ip publik dari perangkat yang digunakan mahasiswa ini berdasarkan pengalaman dari hasil penelitian penulis bahwa semua perangkat yang terkoneksi ke server ternyata mempunyai ip host yang berbeda-beda [15]. Adanya IP address asal host tadi menjadi keunikan karena setiap mahasiswa yang telah melakukan presensi akan direkam hasil hashing IP address asal host tadi. Penerapan kode programnya tampak seperti pada gambar potongan kode program pada Gambar 6.
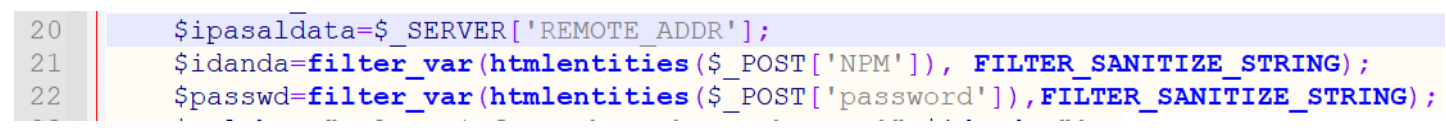

Gambar 7. Kode PHP Perekam IP Host Asal pada File Presensiqr.php.

Pada Gambar 7 baris 20, program pembaca hasil scan kode QR (presensiqr.php) mengambil secara otomatis IP address asal dari perangkat proses presensi yang digunakan mahasiswa. Sementara itu pada baris 21 dan 22 tampak bahwa program mengambil data dari elemen form berupa NPM (Nomor Pokok Mahasiswa) dan password. Form ini tampil setelah program pembaca hasil pindai kode QR diakses URL-nya oleh pemindai kode QR pada perangkat mahasiswa. Tampilan form tersebut tampak pada Gambar 8.

\begin{tabular}{|l|}
\hline Nomor Pokok Mahi \\
\hline Password login sistem akademik anda \\
\hline
\end{tabular}

\section{Gambar 8. Form Identifikasi Mahasiswa Setelah Pindai Kode QR}

Hasil penelitian ini telah diujikan juga proses integrasinya dengan beberapa aplikasi yang digunakan untuk pembelajaran daring di Universitas Muhammadiyah Bengkulu, seperti Learning Management System (LMS) Kelas Kito yang berbasis aplikasi Moodle, Google Classroom, dan beberapa aplikasi Media Sosial yang digunakan oleh dosen dalam berkomunikasi dengan mahasiswanya seperti Whatsapp dan Telegram. Gambar 9, 10, 11 dan 12 membukti hasil pengujian 
JSAI : Journal Scientific and Applied Informatics

Vol. 4, No. 2, Juni 2021, hal. 263 272

E-ISSN: 2614-3054; P-ISSN: 2614-3062, accredited by Kemenristekdikti, Sinta 5

DOI: 10.36085

tersebut. Semua hasilnya menunjukkan keberhasilan proses integrasi yang baik dan sesuai dengan kebutuhan dokumen kinerja dosen yang digunakan di Universitas Muhammadiyah Bengkulu.

Kebutuhan dokumen kinerja dosen selain dibutuhkan oleh pihak Universitas juga dibutuhkan bagi pelaporan beban kerja dosen yang harus dilaporkan setiap periode semester ke Kementerian Pendidikan dan Kebudayaan Republik Indonesia. Bentuk dokumen tersebut dapat dilihat pada Gambar 13.

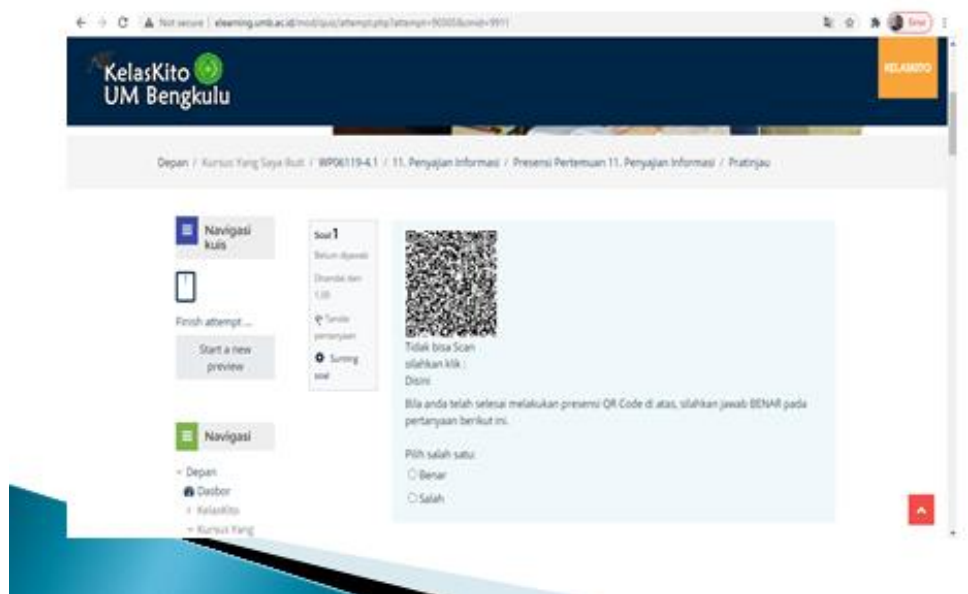

Gambar 9. Tampilan Hasil Integrasi Kode QR Presensi dengan LMS Kelas Kito.
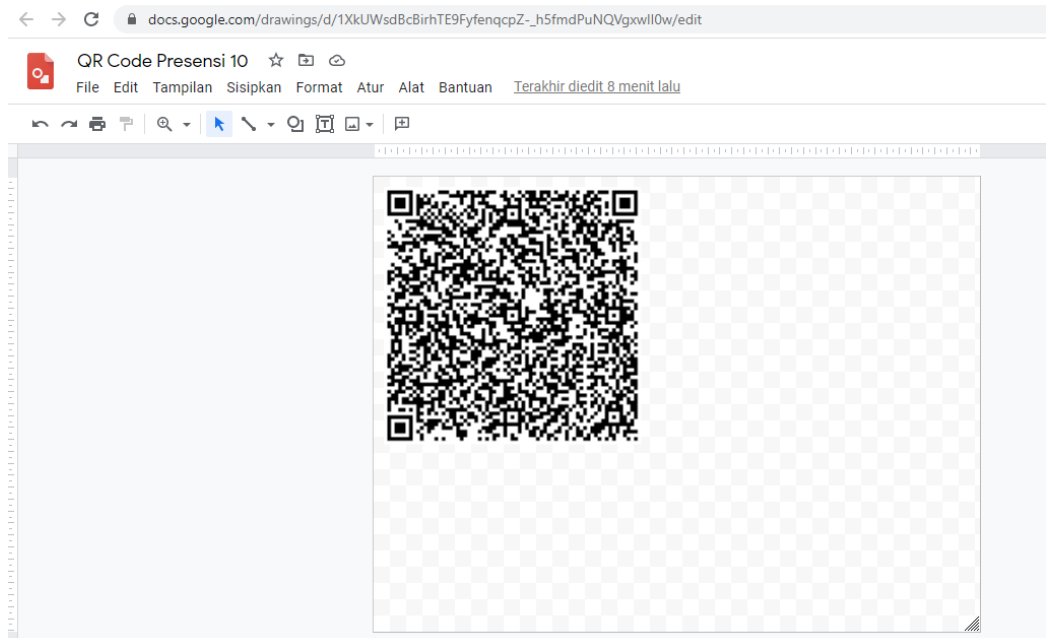

Gambar 10. Tampilan Hasil Integrasi Kode QR Presensi dengan LMS Google Classroom

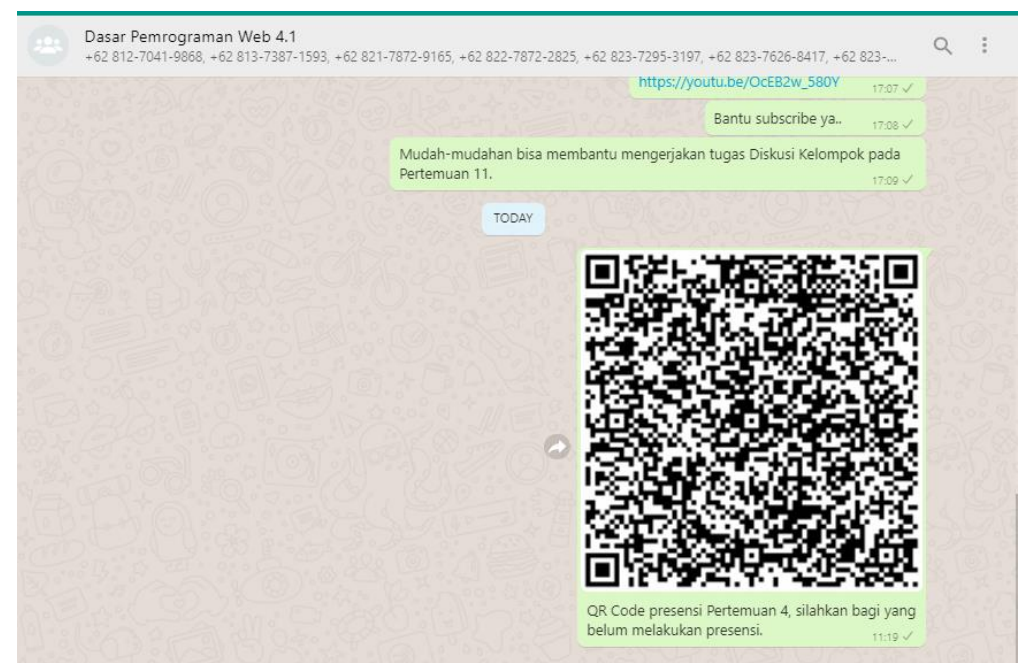

Gambar 11. Tampilan Hasil Integrasi Kode QR Presensi dengan Aplikasi Whatsapp. 


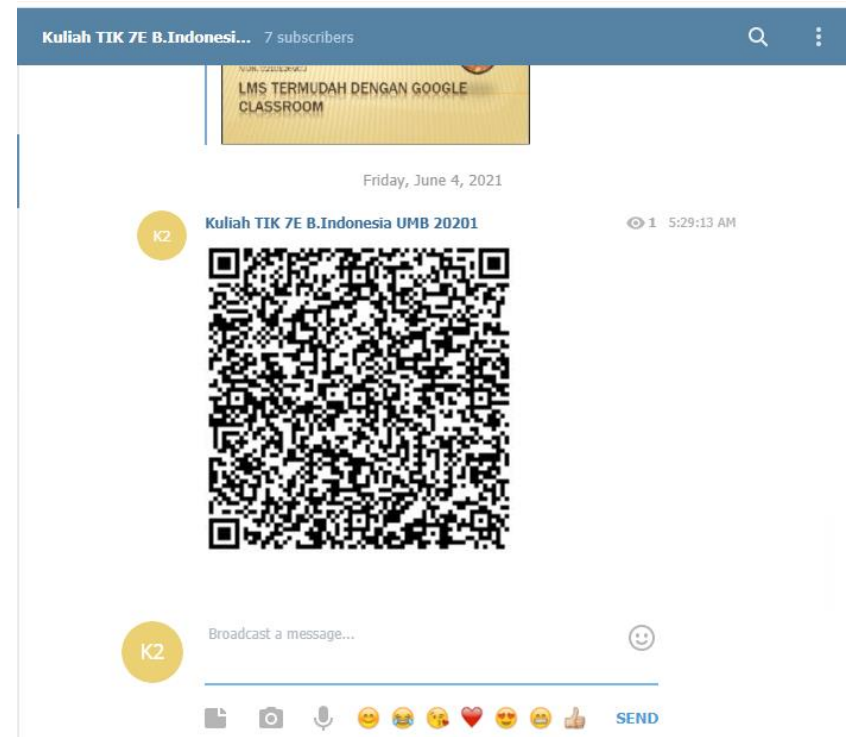

Gambar 12. Tampilan Hasil Integrasi Kode QR Presensi dengan Aplikasi Telegram.

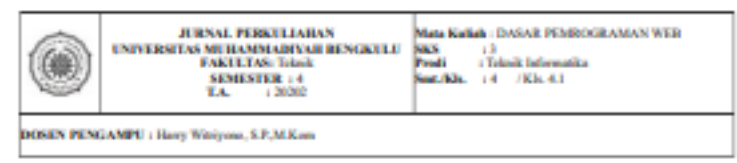

\begin{tabular}{|c|c|c|c|c|}
\hline is & Hai I Imas & $\infty=$ & 践 & Kenawe \\
\hline The & S-2.2nomi & 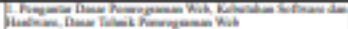 & 39 & \\
\hline & $\sin 30$ & 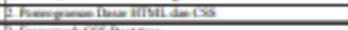 & III & \\
\hline & 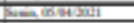 & 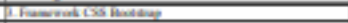 & 15 & \\
\hline t & S-12800m & 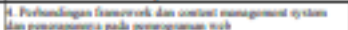 & 16 & \\
\hline 3 & 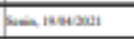 & 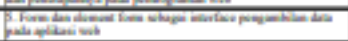 & 13 & \\
\hline 8 & S- abaout & 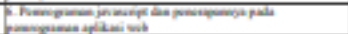 & 16 & \\
\hline & 6-ämoni & 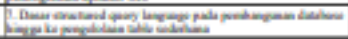 & it & \\
\hline$\Rightarrow$ & 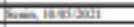 & 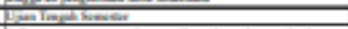 & II & \\
\hline 6 & 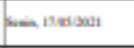 & Pow & 12 & \\
\hline$n$ & S- Suriant & 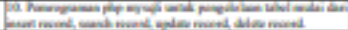 & 13 & \\
\hline & S-lichomi & & 34 & \\
\hline & and 0 & 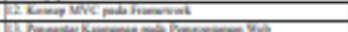 & & \\
\hline & 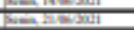 & 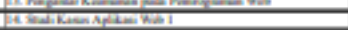 & & \\
\hline & $\operatorname{sensin}$ & 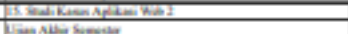 & & \\
\hline
\end{tabular}

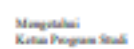

Gambar 13. Hasil Integrasi Presensi Kode QR dengan Laporan Jurnal Perkuliahan.

Selanjutnya untuk menguji keamanan hasil enkripsi dan hashing pada URL yang tersimpan di kode QR, penulis mencobanya dengan aplikasi base64decode.org. Hasilnya menunjukan bahwa proses decoding tetap tidak memberikan tulisan yang dapat dengan mudah terbaca oleh manusia. Bukti tersebut dapat dilihat pada Gambar 14. Selain itu juga dicobakan pada aplikai peretas hashing MD5 yang digunakan sebagai software penguji pada md5online.org. Hasilnya menunjukkan bahwa aplikasi tersebut tidak dapat menguraikan kode hashing MD5 yang tersimpan di kode QR presensi pada penelitian ini. Bukti tersebut dapat dilihat pada Gambar 15. 
JSAI : Journal Scientific and Applied Informatics

Vol. 4, No. 2, Juni 2021, hal. 263 272

E-ISSN: 2614-3054; P-ISSN: 2614-3062, accredited by Kemenristekdikti, Sinta 5

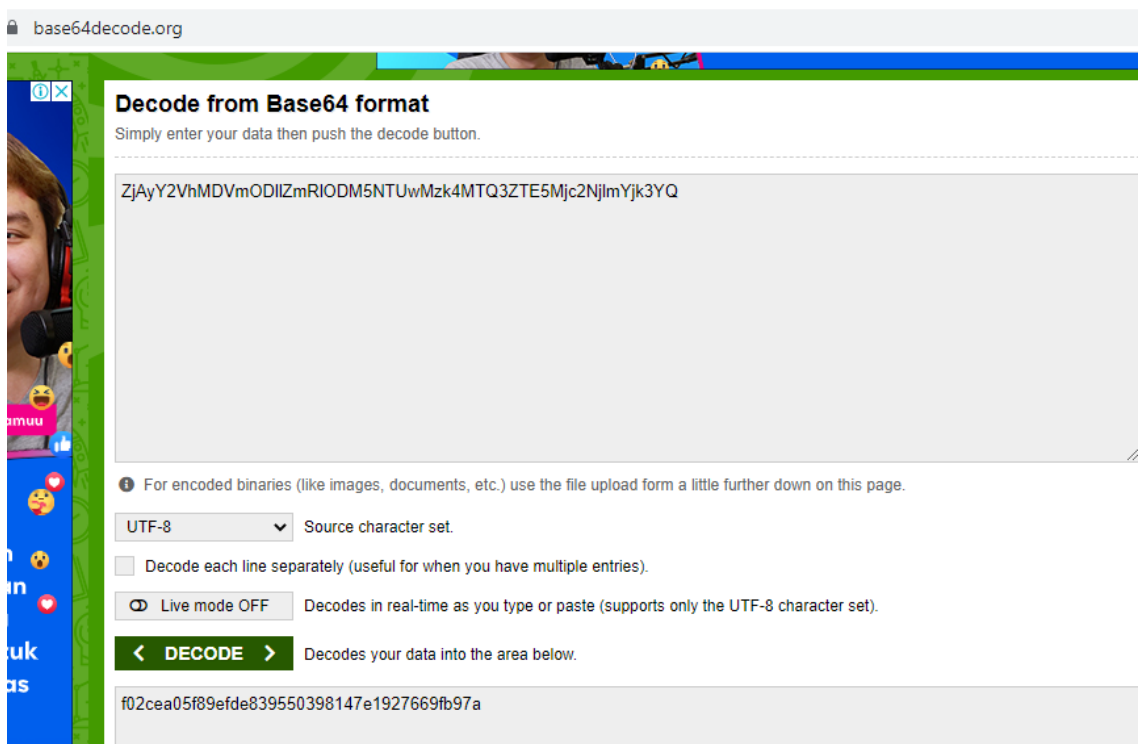

Gambar 14. Hasil Pengujian Decoding Sebagian URI pada Kode QR.

md5online.org/md5-decrypt.html

\section{MD5 Decryption}

Enter your MD5 hash below and cross your fingers :

f02cea05f89efde839550398147e1927669fb97a

Q Quick search (free) $O$ In-depth search (1 credit) 19

\section{Decrypt}

Bad format

Gambar 15. Hasil Pengujian Kode QR Presensi dengan MD5online.org

\section{KESIMPULAN}

Penelitian berhasil menerapkan enkripsi Base 64 dan hasing SHA1 dan MD5 sehingga terbentuk kode QR yang hasil uraian isinya lebih aman karena terenkripsi dan menjadi tulisan yang berisi kode yang tidak dapat langsung dimengerti oleh manusia. Pengurangan kecurangan mahasiswa dalam prosesnya dapat dilakukan dengan penguncian IP address ter-hashing yang tidak dapat langsung diartikan oleh manusia Penggunaan presensi kode $\mathrm{QR}$ membantu memberikan solusi bagi kebutuhan proses presensi perkuliahan sebaga indikator kinerja dosen dan mahasiswa baik pada perkuliahan luring ataupun perkuliahan daring yang menggunakan Learning Management System seperti Moode dan Google Classroom, dan aplikasi media sosial seperti Whatsapp dan Telegram.

\section{UCAPAN TERIMA KASIH}

Penelitian ini dibiayai dari Program Hibah Penelitian dan Pengabdian Dosen Tahun 2020/2021. Terima kasih kami sampaikan kepada Bapak Rektor Universitas Muhammadiyah Bengkulu, Tim Lembaga Penelitian dan Pengabdian Masyarakat Universitas Muhammadiyah Bengkulu, Tim UPT Layanan Teknologi Informasi dan Komputer Universitas Muhammadiyah Bengkulu, dan semua pihak yang telah membantu terlaksananya penelitian ini. 


\section{REFERENSI}

[1] U. Rahardja, O. Sholeh, and F. Nursetianingsih, "Penggunaan dashboard untuk mengontrol kinerja profesionalisme pegawai pada Pt. Sinarmas Land Property," J. Teknol. Inf. dan Multimed., vol. 1, no. 2, pp. 415-418, 2015.

[2] M. Awaluddin, J. angelina Widians, and Masnawati, "Fkti Universitas Mulawarman Berbasis Web," Apl. Daft. Hadir Perkuliahan Mhs. FKTI Univ. Mulawarman Berbas. Web, vol. 2, no. 1, 2017.

[3] A. S. Rintjap, R. U. A. Sherwin, S. St, O. L. St, and J. T. Elektro-ft, "Aplikasi Absensi Siswa Menggunakan Sidik Jari Di Sekolah Menengah Atas Negeri 9 Manado," J. Tek. Elektro dan Komput., vol. 3, no. 3, pp. 1-5, 2014.

[4] Q. Aini, Y. I. Graha, and S. R. Zuliana, "Penerapan Absensi QRCode Mahasiswa Bimbingan Belajar pada Website berbasis YII Framework Application Student Attendance QRCode in Guidance Learn to Website Based on Yii Framework," J. Ilm. SISFOTENIKA, vol. 7, no. 2, pp. 207-218, 2017, [Online]. Available: https://www.neliti.com/id/publications/226282/penerapan-absensi-qrcodemahasiswa-bimbingan-belajar-pada-website-berbasis-yii-f.

[5] K. Aryasa and Y. T. Paulus, "Implementasi Secure Hash Algorithm-1 Untuk Pengamanan Data Dalam Library Pada Pemrograman Java," Creat. Inf. Technol. J., vol. 1, no. 1, pp. 57-66, 2013, Accessed: Jun. 05, 2021. [Online]. Available:

https://ojs.amikom.ac.id/index.php/citec/article/view/298.

[6] E. Gunadhi and A. P. Nugraha, "Penerapan Kriptografi Base64 Untuk Keamanan URL (Uniform Resource Locator) Website Dari Serangan SQL Injection,” J. Algoritm., vol. 13, no. 2, pp. 391-398, 2017, doi: 10.33364/algoritma/v.13-2.391.

[7] S. Sulastri, "Implementasi Enkripsi Data Message Digest Algorithm 5 (MD5) Dan Secure Hash Algorithm (SHA-256) Pada Sistem Penjadwalan Karyawan Agrowisata Setya Aji Flower Farm Bandungan," vol. 5, 2019.

[8] Anonim, "Networking IP filtering and network address translation," IBM Corp., 2013. https://www.ibm.com/docs/en/i/7.3?topic=security-ip-filtering-network-address-translation (accessed Jun. 19, 2021).

[9] L. A. Muharom, "Penerapan Model Presensi Ujian Semester Berbasis Quick Response Code (QR Code) di Universitas Muhammadiyah Jember | Muharom | JUSTINDO (Jurnal Sistem dan Teknologi Informasi Indonesia)," J. Sitem Teknol. Inf. Indones., vol. 1, no. 2, pp. 113-122, 2016, Accessed: Jun. 03, 2021. [Online]. Available: http://jurnal.unmuhjember.ac.id/index.php/JUSTINDO/article/view/572/452.

[10] E. Z. Henry Februariyanti, "Rancang Bangun Sistem Perpustakaan untuk Jurnal Elektronik," $J$. Teknol. Inf. Din., vol. 17, no. 2, pp. 124-132, 2012.

[11] M. I. Sugiarto, A. Linarta, and A. Sofiyan, "Aplikasi Layanan Informasi Absen Dan Nilai Berbasis Sms Gayeway Menggunakan Php Pada Smk Taruna Persada Dumai," I N F O R M a T I K a, vol. 9, no. 2, p. 60, 2019, doi: 10.36723/juri.v9i2.106.

[12] R. Ashford, "QR codes and academic libraries," Coll. Res. Libr. News, vol. 71, no. 10, pp. 526-530, 2010, doi: 10.5860/crln.71.10.8454.

[13] R. T. Fielding, D. Software, and R. N. Taylor, "Principled Design of the Modern Web Architecture," 2000.

[14] Sutriman and B. Sugiantoro, "Analysis of password and salt combination scheme to improve hash algorithm security,” Int. J. Adv. Comput. Sci. Appl., vol. 10, no. 11, pp. 420-425, 2019, doi: 10.14569/IJACSA.2019.0101158.

[15] C. Prihantoro and H. Witriyono, "Perancangan Client Server Three Tier Pada Pembangunan Web Service Anggota Perpustakaan Universitas Muhammadiyah Bengkulu," J. Technopreneursh. Inf. Syst., 2019, doi: 10.36085/jtis.v2i2.355. 